Eur J Health Econom 2005 • [Suppl 1] 6:46-52 DOI 10.1007/s10198-005-0318-x

Published online: 29. October 2005

(c) Springer Medizin Verlag 2005

Aleksandra Torbica · Giovanni Fattore

Centre for Research on Health and Social Care Management, Bocconi University, Milan, Italy

\title{
The "Essential Levels of Care" in Italy: when being explicit serves the devolution of powers
}

The Italian Constitution of 1948 specitaly has a National Health Service based on principles of universalism and comprehensiveness [1, 2]. Established in 1978, the Italian National Health Service (INHS) absorbs $76.4 \%$ of total health care expenditure and it is financed by general taxation (OECD health data, 2005). As a consequence most care is provided free of charge at point of delivery, although user charges apply for outpatient services and procedures and, to a lesser extent, on pharmaceuticals [3].

A major critical feature of the INHS rests on the distribution of powers between the central government and the regions. Mainly created to reverse the concentration of state power occurring during the Fascist regime, the 20 regions are the emerging institutional tier of the country as they benefit from a substantial, although controversial, devolution of powers from the State. They have almost full control over approx. 200 Local Health Units and 100 Independent INHS Hospitals and they are expected to cover their deficit [4]. The Italian Constitution, revised in 2001, reserves to the central government the exclusive power to set the socalled "essential levels of care" (Livelli Essenziali di Assistenza, LEAs), which must be guaranteed to all residents. Regions have virtually exclusive powers over regulation, organization, administration, and funding of publicly financed healthcare. fies the citizen's right to health. This constitutional guarantee is expressed in very general terms. Article 32 of the Constitution says that "The Republic protects health as a fundamental right of the individual and as a concern of collectivity and guarantees free care to the indigent." The principle of a package of benefits available to all citizens irrespective of age, social condition, or income was stated later, in the law introducing the INHS in 1978. The expression "levels of care" was mentioned for the first time with the objective to guarantee equal health care coverage throughout the country: "the State is to set objectives for eliminating geographical differences in social and health care conditions" (Art. 2) and "and to determine levels of care to be guaranteed to all citizens" (Art. 3). The same legislation also introduced another major feature of the INHS: the patient's right to choose "provider and place of treatment."

Although the 1978 reform listed the areas in which treatments are to be delivered under the INHS, it did not define the benefits to be included and excluded in detail. The concept of levels of care gained prominence in the legislation reforming the INHS in 1992-1993. The delegation of new powers to regions was coupled with tighter accountability systems. On the provision side the regions must deliver uni- form levels of care, while on the funding side regions are mandated to cover any deficit required to provide the LEAs and to use their own resources to provide services above those guaranteed by national laws.

The reform laid out a new logical framework, but it took time to establish the LEAs. Significant progress was made in the late 1990 s with the approval of the National Health Plan 1998-200o and a new reform approved in 1999. These emphasized the importance of the principle of equality in the access of care and introduced LEA system; they also clearly stated the criteria that should inform their definition: human dignity, effectiveness, appropriateness, and efficiency.

The LEAs notion was at risk of remaining an abstract concept as political costs and implementation difficulties of clarifying and limiting INHS coverage were paramount. However, substantial progress in the definitions of LEAs was necessary to make sense of the overall strategy of redistribution of powers between the central government and the regions. This progress was made with the agreement between the regions and the central government on 8 August 2001 which was followed by a governmental decree (the LEA decree). At present this decree is the pivotal element of the Italian health benefit catalogue (• Fig. 1). It defines the main 

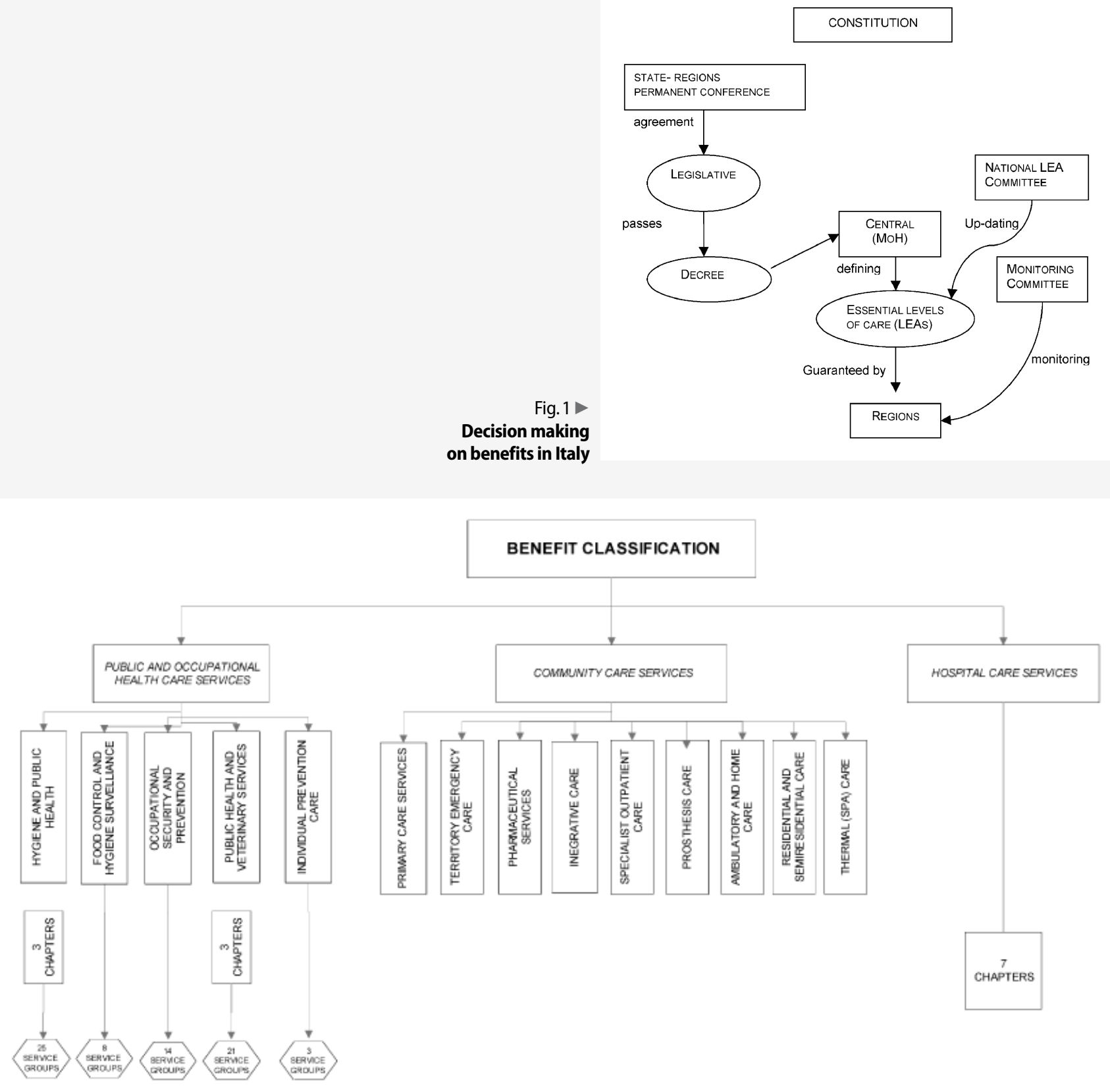

Fig. $2 \triangle$ DPCM, 29 November 2001. Definition of national standards of care (LEAs).

MoH Ministry of Health

areas of healthcare services to be guaranteed by the INHS (positive list), those completely excluded by public coverage (negative list), and those partially covered (only available for specific clinical conditions).

The positive list is based on the recognition and systematization of current legislation (other decrees, laws, guidelines, etc.), i.e., it includes all the services that the INHS is actually providing cate- gorized in three macrolevels of care: (a) public health services, (b) community care, and (c) hospital care (• Fig. 2). $\bullet$ Table 1 displays the main elements of LEA decree and of the other benefit-defining laws and decrees currently in force in Italy. The present contribution focuses on curative services.

The decree also defined a system for monitoring LEA implementation across the country. Responsibility for this was assigned to a special technical body established in April 2002 and composed of representatives of the Ministry of Health, the Treasury, and the regional governments. The main objective of the commission is to "monitor and evaluate the actual provision of services included in the LEAs and their costs."

In 2004 a new technical body (the National LEA Commission) was established to update LEAs on the basis of scientific, 
Eur J Health Econom 2005 - [Suppl 1] 6:46-52 DOI 10.1007/s10198-005-0318-x

○) Springer Medizin Verlag 2005

\section{Aleksandra Torbica - Giovanni Fattore}

\section{The "Essential Levels of Care" in Italy: when being explicit serves the devolution of powers}

\begin{abstract}
The definition of an explicit health benefit package in Italy has gained importance because of devolution of powers from the national level to the regions. The set of services to be guaranteed by the public sector are defined at national level, while regions are accountable for their provision. This contribution discusses the entitlements and the decision criteria adopted by Italian policy-making bodies. Entitlements to services are clearly defined for few sectors (mainly outpatient specialist care); for hospital care the benefit catalogue is vague. The definition of the health benefit package in Italy is an essential element of the relationship between the central government and the regions. It is argued that adequate monitoring systems and accountability procedures are still needed to make the essential levels of care an effective pivotal element of the Italian National Health Service.
\end{abstract}

\section{Keywords}

Health benefit plans - Italy · Health services . Health priorities $\cdot$ National health programs technological, and economic evidence (Ministry decree of 25 February 2005). The Commission is set up of 14 members: 6 experts of healthcare management, planning, and organizational sciences are nominated by the Ministry of Health, 7 are regional representatives, and one is appointed by the Treasury.

\section{Services of curative care in the health benefit basket}

\section{Inpatient curative care}

Traditionally the services to be provided in hospital settings were never explicitly defined by the INHS. It has been rather implicitly recognized that all types of services deemed to be appropriately delivered at hospital level must be available to citizens. The LEA decree defines seven chapters as broad categories of services to be delivered in the hospital: (a) emergency services, (b) ordinary admissions (including rehabilitative and long-term inpatient care), (c) day hospital, (d) day surgery, (e) curative home-care, (f) collection, diffusion, control of blood-components and transfusion services, and (g) organ and tissue transplantation services. In addition, it is explicitly recognized that some benefits are available in hospitals although not included in the positive list of outpatient services provided under public coverage (e.g., certain pharmaceuticals or diagnostic tests).

While the detailed spectrum of services to be provided by the hospitals is not explicitly defined, national and regional feeschedules regulate their funding. Since January 1995 Italian hospitals have been financed mainly according to nationally predetermined rates based on classification into diagnosis-related groups (DRGs) [4, $5,6]$. Regions are free to modify the rates according to their own standards but must take the national rate as the maximum level [1]. To a certain extent DRG lists may be interpreted as the catalogue of hospital services and benefits covered by the INHS. This interpretation, however, should be done with some caution. DRGs are divided in two major groups: surgical and medical. The interventions to which surgical DRGs refer are expected to be offered and funded. Therefore surgical DRGs define a sort of list of services available to patients. For medical DRGs the situation is different as the classification includes all possible diagnoses, including those for which hospital admissions may not been appropriate. Therefore medical DRGs do not define a list of services to be guaranteed but rather economic constraints according to which providers act. Thus, although implicitly, the tariff values assigned to DRGs influence the specific content of the services provided in each diagnosis category.

In Italy as well as in other countries, determining tariffs for specific diagnosis and treatments is seen as detrimental to the adoption of innovative technologies. Fixed and outdated tariffs may discourage the adoption of new expensive technologies and may force hospitals to look for alternative source of funding, often resulting in wide disparities of their availability to citizen. Regional authorities may react to the deficiencies in national policy with a variety of measures as it is illustrated in the case of Drug Eluting Stents (DES). Since their introduction into the European market in 2002, DES have been gradually implemented in clinical practice in Italy, mainly by hospitals in the north of the country. Several position papers and recommendations have been provided by scientific societies (e.g., Italian Group for Heamodynamics Studies, GISE), study groups, local committees (e.g., Emilia-Romagna CardiologyCardiosurgery Committee) in order to guide the adoption of DES. Early updating of reimbursement policies has been advocated by Italian cardiologists, hospital administrators, and patients to allow this technology to be economically sustainable by the hospitals [7]. Faced with continuously growing clinical and economic evidence, some regional authorities started to adopt different policy measures [8]. In 2002 the Lombardy Region revolutionized its DRG classification by creating three new DRGs to cover stent reimbursement and to encourage utilization. Other regions (Emilia Romagna, Lazio, Marche, Puglia) allowed for particular DRG tariff increase while the Campania Region established a special regional fund for DES reimbursement. In addition, Emilia-Romagna and recently Sicily established a regional registry to monitor 
Table 1

Benefit-defining laws/decrees and catalogues for curative care services in Italy (LEAs DPCM, 29 November 2001,

"Definition of Essential Levels of Care"; Specialist DM, 22 July 1996, "Specialist outpatient services"; NPF National

Pharmaceutical Formulary; Prostheses DM 332/1999: "Prosthetic devices, tariffs and provision modalities";

Rehab Guidelines on Rehabilitative Care adopted on May 7th 1998; Primary National Contract for Primary Care)

\begin{tabular}{|c|c|c|c|c|c|c|}
\hline & LEAs & Specialist & NPFa & Prostheses $^{a}$ & Rehab $^{a}$ & Primary \\
\hline Inpatient curative care & + & - & - & - & - & - \\
\hline Day cases curative care & + & - & - & - & - & - \\
\hline Primary care & + & - & - & - & - & + \\
\hline Outpatient dental care & + & - & - & - & - & - \\
\hline Specialist outpatient care & + & + & - & - & - & - \\
\hline Alternative medicine & + & - & - & - & - & - \\
\hline Rehabilitative care & + & - & - & - & + & - \\
\hline Long-term nursing care & + & - & - & - & - & - \\
\hline Clinical laboratory & - & + & & - & - & - \\
\hline Emergency rescue & + & - & - & - & - & - \\
\hline Pharmaceuticals & + & - & + & - & - & - \\
\hline Therapeutic devices & + & - & - & + & - & - \\
\hline $\begin{array}{l}\text { Prevention and public health } \\
\text { services }\end{array}$ & + & - & - & - & - & - \\
\hline Legal status & $\begin{array}{l}\text { Legislative } \\
\text { decree }\end{array}$ & Ministry Decree & $\begin{array}{l}\text { Agency } \\
\text { administrative act }\end{array}$ & $\begin{array}{l}\text { Legislative } \\
\text { decree }\end{array}$ & Law & $\begin{array}{l}\text { Presidential } \\
\text { decree }\end{array}$ \\
\hline Decision maker & $\begin{array}{l}\text { Permanent } \\
\text { State-Regions } \\
\text { Conference; MoH }\end{array}$ & Ministry of Health & $\begin{array}{l}\text { National Drug } \\
\text { Agency }\end{array}$ & $\begin{array}{l}\text { Ministry of } \\
\text { Health }\end{array}$ & $\begin{array}{l}\text { Ministry of } \\
\text { health }\end{array}$ & $\begin{array}{l}\text { Ministry of health; } \\
\text { Trade-Unions of } \\
\text { GPs }\end{array}$ \\
\hline Original purpose & Entitlements & Fee-schedule & Positive list & Fee-schedule & Guidelines & Entitlements \\
\hline $\begin{array}{l}\text { Positive/negative definition } \\
\text { of benefits }\end{array}$ & $P$ and $N$ & $\mathbf{P}$ & $\mathbf{P}$ & $\mathbf{P}$ & $\mathbf{P}$ & $\mathbf{P}$ \\
\hline Degree of explicitness ${ }^{b}$ & 2 & 3 & 3 & 3 & 1 & $1 / 2$ \\
\hline $\begin{array}{l}\text { If itemized: goods, procedures } \\
\text { only; linked to indications }\end{array}$ & $\begin{array}{l}\text { Varies by area } \\
\text { of care }\end{array}$ & $\begin{array}{l}\text { Procedures, } \\
\text { sometimes linked } \\
\text { to indications }\end{array}$ & $\begin{array}{l}\text { Goods, for certain } \\
\text { categories specific } \\
\text { indications } \\
\text { (prescription notes) }\end{array}$ & Goods & No & Partially \\
\hline Updating & Foreseen & $\begin{array}{l}\text { No at national } \\
\text { level; regular at } \\
\text { regional level }\end{array}$ & $\begin{array}{l}\text { Regularly } \\
\text { (annually) }\end{array}$ & No (foreseen) & No & Every $2-3$ years \\
\hline Criteria & - & - & - & - & - & - \\
\hline • Need & + & - & - & + & - & + \\
\hline - Costs & + & + & + & + & - & - \\
\hline - Effectiveness & - & + & + & - & - & + \\
\hline - Cost-effectiveness & - & - & - & - & - & - \\
\hline - Budget & + & - & - & - & - & + \\
\hline - Appropriateness & + & - & - & - & + & + \\
\hline
\end{tabular}

the rate of adoption of the new technology and its effectiveness in real-life conditions. The final aim is to identify the target populations for which the new technology would be most beneficial. Most of the regions still have not updated in any way their reimbursement policies, thus limiting to certain extent the diffusion of the device on their territory.
The example on DES illustrates the existence of wide variations across the regions concerning how to fund innovative technologies. Similar situations may be found in other sectors of health care. However, 
the issue is not that simple when we consider that one of the fundamental rights of Italian citizens is the "freedom of choice of provider and place of care" [9], making regions responsible for the cost of treatment provided to their residents in other regions.

\section{Day cases of curative care}

Services available in day hospital regime are defined as "diagnostic, rehabilitation, and curative care, delivered as alternative to ordinary hospitalization, when the services to be provided require, due to their nature or complexity of provision, medical or/and nurse continuous assistance, not available in the outpatient (ambulatory) setting" (Presidential decree, 20 October 1992). Regarding inpatient care services available in day hospital are not explicitly defined, but rather there are specific criteria for the service to be considered appropriately delivered in this regime. Guidelines are defined at national level and they refer mostly to organizational aspects of services' provision rather than their specific types (i.e., number of beds assigned for day hospital services must be at least 10\% of the total).

The situation is very similar as regards day surgery care. National guidelines provide a list of possible interventions that may be performed in day care setting, as an alternative to normal hospital care. The list includes about 780 interventions, itemized by service delivered and grouped according to the organ or system of organs they refer to (e.g., respiratory system interventions, cardiovascular system interventions)

\section{Outpatient curative care: primary care}

All patients in Italy are registered with a general practitioner (GP) or a pediatrician who is in charge for providing most primary care, referring to specialists, and prescribing diagnostic interventions and drugs. The citizen's can freely choose his or her own GP, given the limit of maximum number of enrolled patients. Primary care services provided by GPs are outlined broadly in the National Contract for General Practitioners, which is the most important document regulating various aspect of primary care. The National Contract is a result of negotiations between the government and representatives of general practitioners organized in various trade unions. Once reached, the content of the National Contract is legislated through a Decree approved by the Ministry of Health (i.e., the agreement is a binding by law). Regions are autonomous in establishing further agreements (Accordi Integrativi Regionali) aimed mainly at identifying the most appropriate organizational arrangements for the provision of services set at national level. The regional agreements may define additional services to be provided in primary care. The categories of services that primary care physicians are obliged to provide under the National Contract are defined broadly as: (a) essential services: acute and chronic disease management, in line with best practice indications and in agreement with the patient; (b) health promotion activities; (c) patient management within programmed and integrative domiciliary care coordinated with providers of specialist and rehabilitative care services; and (d) community services defined on the basis of regional agreements. The $\mathrm{Na}$ tional Contract also encourages various forms of integration between primary care physicians and district services such as social and home care. Additionally, the National Contract obliges Local Health Units to guarantee continuity of care, i.e., primary care services $24 \mathrm{~h}$ a day, 7 days a week. Organizational arrangements are decided at regional level.

\section{Outpatient dental care}

Public coverage of dental care services has always been a debated issue in the Italian NHS. Current legislation explicitly excludes almost all types of dental services from the nationally defined benefit package. Some limited care is available to special groups of patients defined according to age and to specific clinical conditions. This explicit and rather broad exclusion of dental care services at national level had an impact on regional health policies. Numerous regions have adopted measures to guarantee some types of dental care services to citizens. An example of regionally defined benefit catalogue for dental care services is that in Veneto region, defined by Regional decree 2227/02. The regional decree defines the list of services available free of charge or subject to copayment for special patient categories. The list of services is available under set conditions only for the residents of Veneto Region, while nonresidents are fully charged. Beneficiaries are identified according to age, income, employment status, and presence of specific disease criteria: (a) dental health care in developmental age (o-16 years): preventive, diagnostic, and curative services for patients under the age of 16 years, orthodontic care for patients under the age of 12, nonsurgical treatment of paradental pathology for patients under age 16; (b) dental and prosthetic care to very low-income residents $(<€ 8,500$ per year) affected by chronic (e.g., cardiac insufficiency, psychosis) and rare (e.g., metabolic diseases, immunodeficiency) conditions; and (c) specialist curative care (excluding prosthetics) for anthalgic emergency cases caused by infections of caries and of paradental pathologies of traumatic events.

\section{Specialized outpatient care}

Specialized ambulatory services, including specialist visits, diagnostic, and curative interventions, are provided either by LHUs or by accredited public and private facilities. Patients are allowed to access specialist care only after approval by their general practitioner, who is responsible for the referral. Once the general practitioner has authorized the visit or the procedure, the patient is free to choose any provider among those accredited by the NHS anywhere in Italy. A list of outpatient services, including diagnostic procedures, specialist visits and laboratory tests was drawn up in 1996, and its original purpose was to define reimbursement fees of providers. Since then the national list of services has not been updated. However, regional authorities have often revised their fee schedules. The main criteria including services are effectiveness (based on solid scientific evidence) and costs. The benefits are classified in three different sections: (a) specialist outpatient care (including clinical laboratory and diagnos- 
tic imaging) provided under INHS coverage (a positive list of services, explicitly defined and enumerated, mainly without specific link to clinical conditions); (b) specialist services available only for specific indications (positive list of services limited to special patient categories); and (c) specialist outpatient care not covered by the INHS (negative list).

Regions are free to deliver additional services for which they are financially responsible. These services should be marked separately in the fee schedule and added to the list in accordance with the coding system in place. The positive list of specialist outpatient services is itemized by service delivered. The items (approx. 2,00o) are grouped into 16 categories on the basis of system of organs the intervention refers to (e.g., respiratory system interventions). Each category is further divided according to the specific organ (e.g., trachea and larynges interventions). Finally, each subcategory contains a list of specific services (e.g., laryngoscope). Some services in the positive list are limited to special settings (e.g., where special equipments are available). Services that are available only to special patients categories (i.e., limited for specific clinical conditions) include about 20 items, mainly laboratory and diagnostic examinations that are very costly (e.g., positron emission tomography) or in some way controversial (palliative pain treatments).

\section{All other outpatient curative care}

Numerous services of physiotherapy are excluded from the national benefit package. Many regions, however, have approved their inclusion in the regional benefits so to generate substantial variability across the country. Lombardy, for example, includes all services listed on the national negative list while Veneto and Friuli Venezia Giulia authorize "water rehabilitation." Almost all regions provide anthalgic electrotherapy, ultrasound therapy, mesotherapy, and laser therapy. The national benefit package explicitly excludes all types of alternative and complementary medicine, leaving it to the regions to decide whether to provide some of these services to their citizens. Only 4 of 21 the regions have invested in this category of services: (a) acupuncture is available in
Piedmont, Valle d'Aosta, Umbria, and Tuscany; (b) homeopathy is available in Valle d'Aosta (limited to specific clinical conditions); and (c) chiropractic services are available in Valle d'Aosta only for spinal cord pathologies. Spa treatment is available for a limited number of pathologies, identified as those for which thermal treatment may provide actual benefits (based on scientific evidence). The list of pathologies is explicitly defined in a Ministry decree (1994) and includes: rheumatic diseases (e.g., osteoarthrosis and other degenerative forms, extrajoint rheumatisms), respiratory diseases (e.g., chronic pulmonary diseases), and dermatological diseases (e.g., psoriasis).

\section{Discussion}

Almost 40 year since its inception, the Italian NHS has an explicit system of national services guaranteed to all its citizens. The concept of providing a limited set of services under the INHS is now well established. Entitlements to services in particular areas (mainly outpatient care) are now clearly defined, and some services (e.g., dental and thermal care) are explicitly excluded. In the area of hospital care entitlements remain broad and general, although a strong reference to appropriateness criteria and the use of DRGs contribute to make benefits more explicit in this setting as well.

As in other countries, in Italy a clear definition of the benefits provided by the statutory system is thought to be beneficial for several reasons: it can contribute to a better allocation of resources, help to reassure patients about their rights and responsibilities, and facilitate the development of supplementary insurance [9]. In addition, the definition of the health benefit package in Italy is also an essential element in the relationship between the central government and the regions. The system of LEAs is the means to keep management and policy powers at regional level while assuring national guarantees. In this sense the basic package is primarily a policy devise to keep regions accountable to national standards.

A constitutional reform aimed at a new redistribution of powers between the central and regional authorities is presently under parliamentary discussion. This specifies that powers on health matters are exclusively in the hands of regions, provided that national principles are respected. If this reform is approved, the basic package would gain even more importance. Therefore we foresee the need for substantial investments to further specify the content of the package and, more importantly, to develop adequate monitoring systems and accountability procedures.

In our opinion, two issues are particularly critical in this respect. First, the coherence between benefits and resources made available requires an adequate governance system. At present Italy does not have a higher Chamber (it may be introduced in the Constitution reform under discussion) in which regions are represented, and where negotiations between them and the central government can take place within an appropriate institutional framework. At present, the devolution process lacks adequate rules to govern negotiations and conflicts. The risk of institutional conflicts, endless negotiations, legal disputes, and lack of coordination is very real and hitherto affects mainly the health care sector. It should be clear that without adequate governance mechanisms conflicts between the two central and regional authorities and between the regions themselves may result in further acceleration of the fragmentation of the INHS. The second issue concerns an adequate infrastructure to sustain the national government as guarantor of health care rights. Without an appropriate information system and new jurisdictional powers the national tier cannot ensure its guarantor role. To implement effective national guarantees the central government needs to develop the benefit package, to implement an effective monitoring system, and to design appropriate rules to force regions to act adequately. On the other hand, these conditions are also needed to ensure that resources available to the regions are compatible with the cost of the provision of services included in the benefit package [10].

It has been suggested that LEAs serve two main policy goals: equality and costcontainment [11]. An explicit definition of the guarantees provided Italians is a major mechanism to promote equality in the ac- 
cess of care, while limiting coverage may be a strong tool to contain costs. In theory the two objectives are compatible as explicitness of coverage can coexist with a different extent of the benefit package. In practice, however, LEAs may results in an overall system to defend the basic principle of the INHS from the risk of poor funding. Should radical policies aimed at reducing the ambitious goals of the INHS prevail, LEAs may become the main pillar of the system.

A few reflections can be made about the criteria adopted in Italy to build the benefit package. Effectiveness (in most cases efficacy), as confirmed by scientific evidence, is the dominant criterion in defining the package. Need criteria have been also used; ailments for minor conditions (cough, sore throat, minor headache), cosmetic surgery, and ritual circumcisions) are excluded on the basis of various interpretations of the need criteria. In general, clinical and organizational appropriateness is promoted as well. As the former requires that treatments and procedures are applied only to patients with particular clinical conditions, the latter tries to assure that patients are treated in the most adequate (and often cheapest) setting. Overall the use of appropriateness criteria suggests that benefit catalogues should be made of detailed lists of services for particular clinical conditions rather than simple lists of services.

\section{Corresponding author Aleksandra Torbica}

Bocconi University, Milan, Italy e-mail: aleksandra.torbica@unibocconi.it

\section{Acknowledgements}

The results presented here are based on the project "Health Benefits and Service Costs in Europe-HealthBASKET" which is funded by the European Commission within the Sixth Framework Research Programme (grant no. SP21-CT-2004-501588).

\section{References}

1. Donatini A, Rico A, D'Ambrosio MA et al (2001) Health care systems in transition - Italy. WHO on behalf of the European Observatory on Health Care Systems: Copenhagen

2. France $G$, Taroni $F$ (2005) The evolution of healthpolicy making in Italy. J Health Politics Policy Law 3:169-187

3. Anessi-Pessina E, Cantù E, Jommi C (2004) Phasing out market mechanisms in Italian National Health Services. Public Money Manag 24:309-316

4. Anessi-Pessina E, Cantù E (2004) Rapporto OASI 2004: L'aziendalizzazione della sanità in Italia. Egea: Milan

5. Fattore $G$ (1999) Cost-containment and reforms in the Italian National Health Service. In: Mossialos E, Le Grand J (ed) Health care and cost containment in the European Union. Ashgate: Aldershot, pp 513-546

6. Taroni F (1996) DRG-ROD nuovo sistema di finanziamento degli ospedali. II Pensiero Scientifico: Roma

7. Tarricone R, Marchetti M, Lamette M et al (2004) What reimbursement for coronary revascularization with drug-eluting stents? Eur J Health Econ 5:309-316

8. Sangiorgi G, Rodami P, Airoldi F, Colombo A (2005) Stent a rilascio di farmaco: dai risultati degli studi clinici ai modelli di impatto economico-sanitario nella realtà italiana. Ital Heart J [Suppl 6]:145-156

9. Del Vecchio M (1997) Guaranteed entitlement to health care: an Italian point of view. In: Lenaghan $J$ (ed) Hard choices in health care. BMJ Books: London

10. Fattore G (1999) Clarifying the scope of Italian NHS coverage: Is it feasible? Is it desirable? Health Policy $50: 123-142$

11. France $G$ (2003) I livelli essenziali di assistenza: un caso italiano di policy innovation. In: Fiorentini G (ed) I servizi sanitari in Italia 2003. II Mulino: Bologna 